\title{
Программы РФ по поддержке промышленного экспорта: некоторые наблюдения
}

За последние несколько лет в России принято свыше 20 различных нормативных документов, нацеленных на развитие промышленного потенциала страны и диверсификацию ее экспорта. Среди этих документов Энергетическая стратегия до 2030 года, принятая в 2009 г., Стратегия развития черной металлургии, Стратегия развития цветной металлургии, Стратегия развития I Т - отрасли,

Полуэктов Александр Борисович - главныци эксперт Института торговой политики НИУ ВШЭ, кандидат экономических наук, работал в Постоянном представительстве России при ЕС, а также в органах, ответственных за внешнеэкономические связи. 
Транспортная стратегия, Стратегия развития пищевой и перерабатывающей промышленности. Особенно напряженным в этом смысле стало 15 апреля 2014 г., когда Правительство одномоментно приняло Государственную программу экономического развития и инновационной экономики, Государственную программу развития промышленности и повышения ее конкурентоспособности, Государственную программу развития электронной и радиоэлектронной промышленности, Государственную программу развития авиационной промышленности, Государственную программу развития образования.

Поскольку перечисленные документы разработаны и утверждены сравнительно недавно, оценивать их эффективность было бы преждевременно, особенно в условиях развернувшегося экономического кризиса. Однако программы поддержки и развития экспорта промышленной продукции реализуются в России уже в течение целого ряда лет. Так, составной частью Федерального закона № 157-Ф3 «О государственном регулировании внешнеторговой деятельности в Российской Федерации», принятого еще в октябре 1995 г., является гл. 6, специально посвященная вопросам поддержки промышленного экспорта. Иными словами, последовательная деятельность государства в данной области началась фактически 20 лет тому назад.

За Федеральным законом 1995 г. последовал Федеральный закон от 8 декабря 2003 г. № 164-Ф3 «Об основах государственного регулирования внешнеторговой деятельности», в котором тема стимулирования промышленного экспорта была развернута значительно шире. В частности, в нем подробно прописаны сферы компетенции Правительства РФ и органов исполнительной власти субъектов РФ. Так, согласно данному закону им поручены обеспечение кредитования участников внешнеторговой деятельности и функционирования системы гарантий и страхования экспортных кредитов, организация торговых выставок и ярмарок, проведение кампаний по продвижению российских товаров и услуг на мировые рынки, принятие мер по созданию благоприятных условий для доступа российских лиц на рынки иностранных государств.

В октябре 2003 г. Правительство РФ также приняло распоряжение № 1493-р, в котором изложена Концепция развития государственной финансовой (гарантийной) поддержки экспорта промышленной продукции. Главной целью такой поддержки являлось усиление позиций российских экспортеров промышленной продукции на внешнем рынке и увеличение в структуре экспорта доли изделий с высокой степенью переработки. В частности, в распоряжении содержатся меры, регулирующие порядок предоставления государственных гарантий экспорту промышленной продукции, а также и экспортному кредитованию меры по возмещению части процентных ставок по экспортным кредитам российских кредитных организаций. Этот документ до сих пор остается основным нормативным актом в данной области.

В сентябре 2004 г. Правительство РФ приняло распоряжение № 1222-р, содержавшее перечень продукции, на которую распространяется государ- 
ственная гарантийная поддержка экспорта. Интересно отметить, что если по позициям, относящимся к сельскохозяйственным товарам, таким как пшеничная мука или мясные продукты, в распоряжении речь идет лишь об отдельных видах товаров, классифицируемых на уровне четырех-шести знаков Товарной номенклатуры внешнеэкономической деятельности (ТН ВЭД), то для промышленных товаров (ядерные котлы, электрические машины и оборудование, железнодорожный транспорт, средства наземного транспорта, самолеты, мебель и т.д.) государство поставило гораздо более амбициозную задачу: продвижение экспорта практически по всему ассортименту продукции. В этом документе указываются не отдельные товарные позиции, а целые главы перечня промышленных товаров (гл. 82, $84,85,86$ и др.).

Кроме того, в Дорожной карте по поддержке доступа на рынки зарубежных стран и поддержке экспорта (принятой распоряжением Правительства РФ от 29 июня 2012 г. № 1128-p), принятой в развитие предыдущих нормативных документов, отмечается, в частности, что ее реализация призвана обеспечить успешное продвижение российского несырьевого экспорта на рынки зарубежных стран, внедрение и закрепление новых видов продукции на новых рынках, что будет способствовать диверсификации экспорта, повышению его вклада в модернизацию отечественной экономики, обеспечению устойчивого хозяйственного роста. Как указывается в документе, в результате выполнения Дорожной карты «будет сформирована стимулирующая экспорт институциональная среда, обеспечивающая конкурентоспособные условия деятельности российских компаний на мировом рынке». Кроме того, в Дорожной карте установлены конкретные количественные показатели ожидаемого расширения экспорта промышленной продукции. Например, по сравнению с уровнем 2012 г., когда была принята первая редакция Дорожной карты, индекс роста стоимости экспорта промышленной продукции высокой степени обработки в 2013 г. должен был составить 10\%, в 2014 г. - 20 и к концу 2015 г. - 36\%. Иными словами, перед экспортной промышленной политикой, сформированной на базе принятых документов, поставлены весьма амбициозные задачи.

Таким образом, к настоящему времени в России создана система поддержки промышленного экспорта, соответствующая мировому опыту и включающая меры как финансовой поддержки, так и нефинансовой. Схематически ее можно изобразить так, как это представлено на рис. 1.

К финансовым мерам относится система финансирования экспортных операций через структуры Внешэкономбанка, которые функционируют с 1994 г. (ВЭБ, Росэксимбанк). В 2011 г. было создано Агентство по страхованию экспортных кредитов (ЭКСАР). В настоящее время структуры, ответственные за финансирование и страхование экспортной деятельности, объединены в один центр по гарантийной поддержке, что должно облегчить деятельность экспортеров по выходу на внешние рынки. 

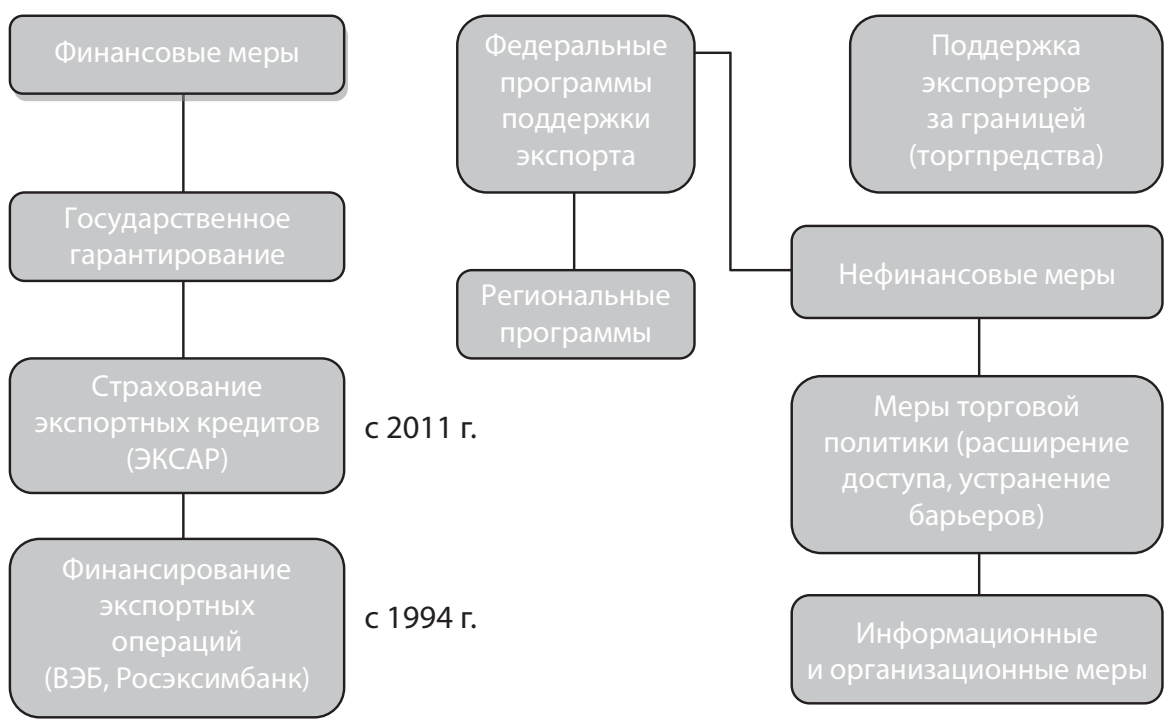

Рис. 1. Система поддержки экспорта.

В области нефинансовых мер поддержки промышленного экспорта была проведена большая работа по созданию информационных баз, специализированных порталов в Интернете, а также по развертыванию сети консультативных услуг. Отдельно следует отметить недавнее вступление России в ВТО, членство в которой должно позволить, в частности, более эффективно бороться с барьерами в торговле и расширять доступ российской промышленной продукции на внешние рынки.

Несколько особняком в приведенной выше схеме стоит система российских торговых представительств за рубежом (в настоящее время их насчитывается более 50), которые проводят большую и полезную работу по сбору экономической и конъюнктурной информации, анализу рынков, оказанию практической помощи отечественным компаниям.

Однако, несмотря на предпринятые в последние годы усилия, эффективность действующей системы поддержки промышленного экспорта остается чрезвычайно низкой, о чем ярко свидетельствует динамика структуры российского экспорта в развитые страны за два последних десятилетия (рис. 2).

По нашему мнению, именно экспорт в развитые страны является тем универсальным индикатором, который отражает конкурентоспособность нашей экспортной продукции, ее востребованность на мировых рынках, степень ее соответствия современным требованиям. Приведенный выше график вряд ли может свидетельствовать о благополучном положении дел в этой сфере и соответственно о действенности системы поддержки экспорта. Со второй половины 1990-х годов идет устойчивое снижение доли нашего экспорта промышленной продукции на рынки развитых стран и столь же неуклонное увеличение в нем доли топлива. 


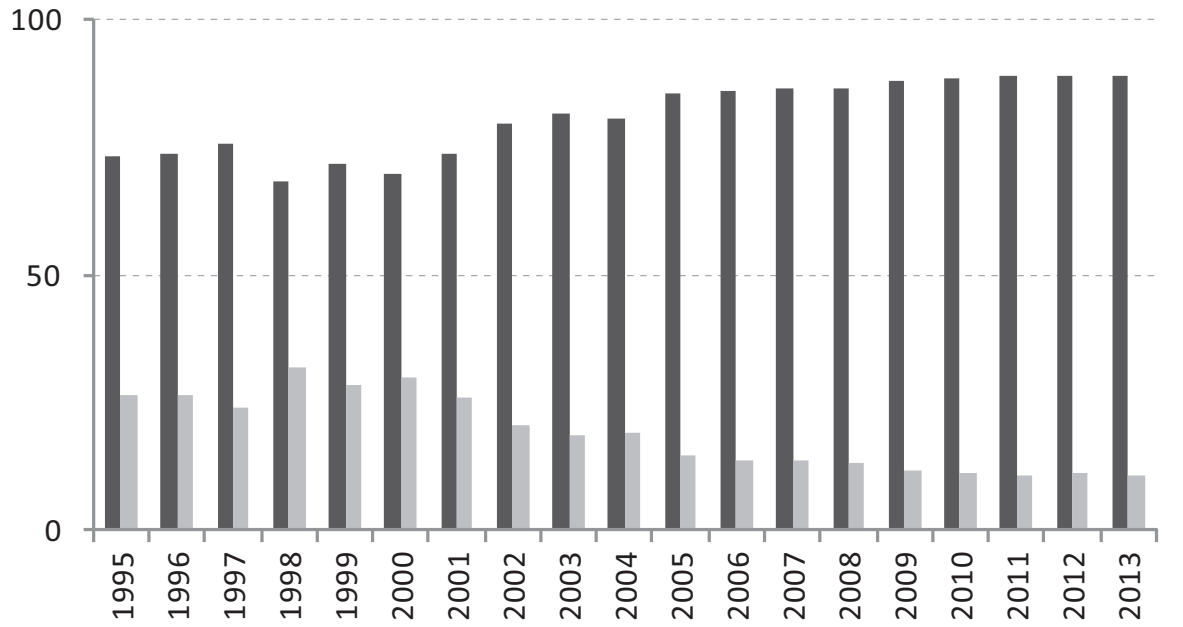

Рис. 2. Структура экспорта России в развитые страны в 1995-2013 гг., \%: топливо (SITS, ch. 3); промышленная продукция (SITS, ch. 5-8, без р. 667-680)

Источник: данные ЮНКТАД.

Для построения графика была использована Стандартная международная торговая классификация (SITC) экономических организаций системы $\mathrm{OOH}$, гл. 3 которой содержит все топливные товары: газ, нефть, уголь. Что касается промышленной продукции, то вся номенклатура готовых товаров содержится в четырех главах SITC (5-8), в которые включены все возможные готовые изделия: от пряжи и кирпичей до химических изделий, продукции черной металлургии и машиностроения. Таким образом, даже самый общий, агрегатный подход к экспорту нашей промышленной продукции свидетельствует о неуклонном снижении доли промышленного экспорта на рынки развитых стран. Если в 1995 г. доля экспорта промышленной продукции достигала $26,7 \%$, то к 2013 г. она снизилась до 10,7\%, т.е. В 2,5 раза. Очевидно, что такая динамика резко контрастирует с амбициозными показателями роста стоимости экспорта промышленной продукции высокой степени обработки, запланированными в Дорожной карте, о которой шла речь выше.

Примерно такая же удручающая картина с российским экспортом промышленной продукции наблюдается и на рынках развивающихся стран, а это свыше 150 государств, т.е. подавляющая доля стран мира (рис. 3).

Если еще в конце 1990-х годов промышленный экспорт на рынки названных стран превышал наш сырьевой экспорт, то в начале 2000-х эти доли сравнялись, после чего продолжилось резкое и неуклонное падение доли промышленного экспорта в торговле России с развивающимися странами. В результате за последние примерно 20 лет удельный вес промышленной продукции в российском экспорте даже на эти не самые «придирчивые» рынки снизился с 67,8 до $29,2 \%$, т.е. В 2,3 раза. 


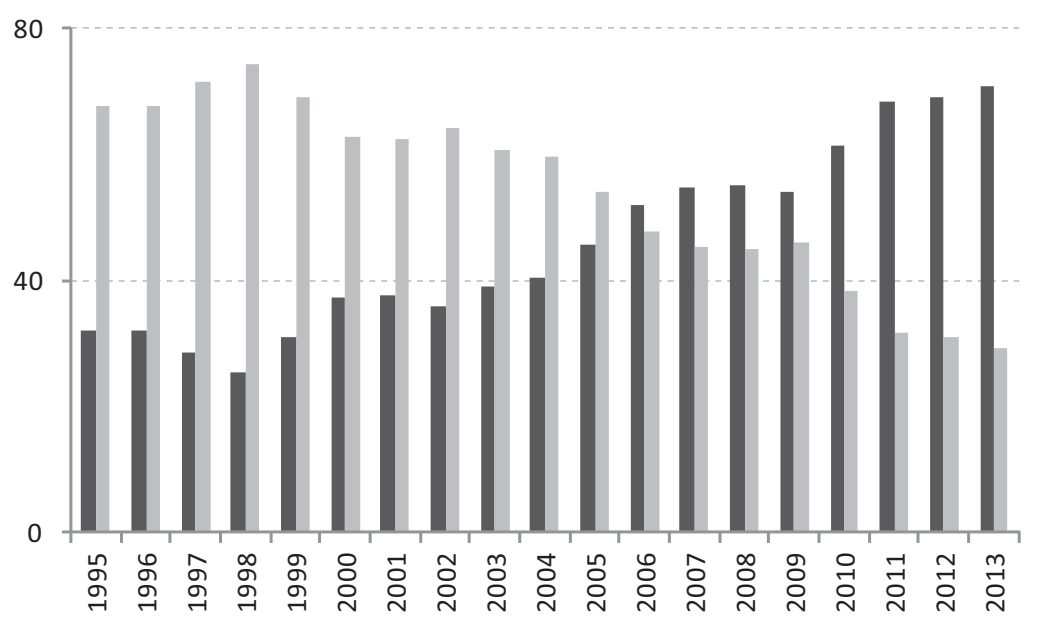

Рис. 3. Структура экспорта России в развивающиеся страны в 1995-2013 гг., \%:

топливо (SITS, ch. 3); промышленная продукция (SITS, ch. 5-8, без р. 667-680)

В связи с этим возникает вопрос о преимущественных географических направлениях экспорта российской промышленной продукции. На рис. 4 приведена структура российского экспорта в страны - члены ЕАЭС. Как видно из рис. 4, российская промышленная продукция, «вымываемая» с рынков как развитых, так и развивающихся стран, на которых фактически идет процесс деиндустриализации нашего экспорта, находит спрос в странах ЕАЭС.

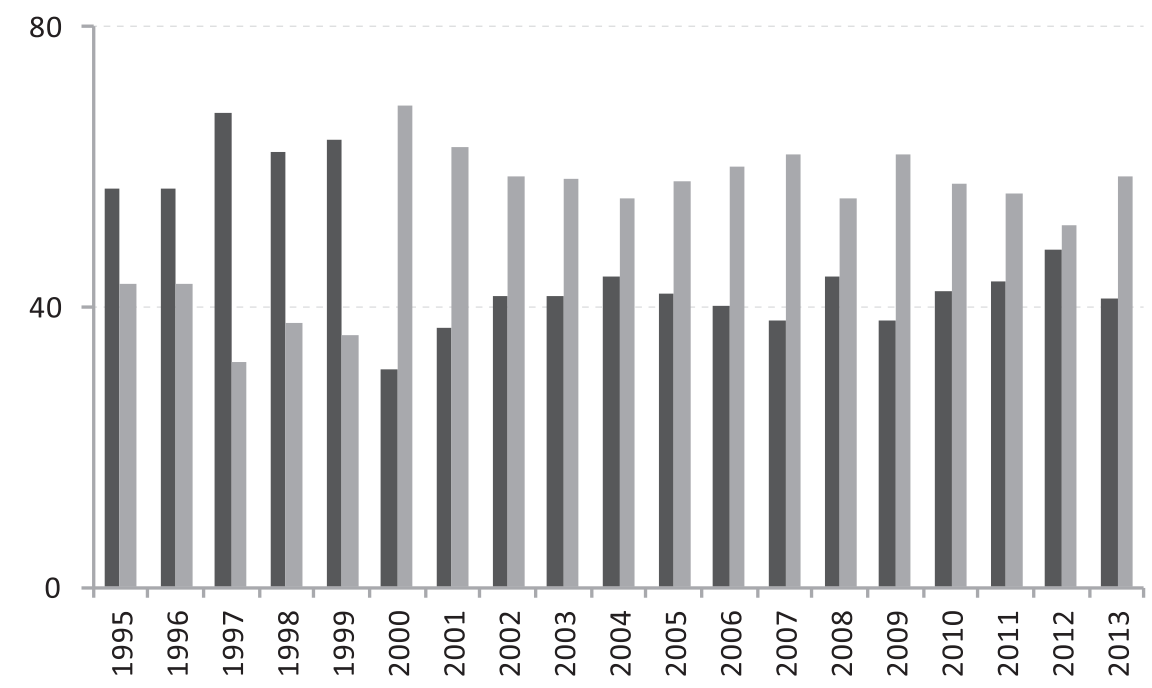

Рис. 4. Структура экспорта России в страны ЕАЭС в 1995-2013 гг::

топливо (SITS, ch. 3); п промышленная продукция (SITS, ch. 5-8, без p. 667-680) 
Так, по итогам 2014 г. 49,7\% российского экспорта в страны-члены ЕАЭС составили промышленные товары, а на экспорт энергоресурсов пришлось 50,3\%. В этом отношении, пожалуй, особо выделяется Армения, ставшая членом ЕАЭС, российский экспорт в которую является преимущественно промышленным (94,5\%).

Иными словами, российские готовые товары, не находящие спроса на рынках развитых и развивающихся стран в силу недостаточно высокой конкурентоспособности, поступают на рынки стран ЕАЭС. Тем самым практически создается некий «анклав», в рамках которого идет обмен товарами, не востребованными на мировом рынке, что с неизбежностью ведет к консервации технологического отставания. Это обстоятельство тем более неудовлетворительно, что на страны ЕАЭС приходится в совокупности лишь около 7,5\% общего объема внешней торговли России, т.е. речь идет об относительно небольших объемах поставок промышленной продукции. Львиная доля товарооборота России (свыше 50\%) традиционно приходится на ЕС.

Означает ли это, что благодаря своей обеспеченности богатыми природными ресурсами Россия обречена на то, чтобы заниматься лишь экспортом углеводородов и прочего сырья? Опыт ряда ведущих ресурсообеспеченных стран, таких как США, Канада, Норвегия, показывает, что наличие богатых природных ресурсов отнюдь не предопределяет сырьевую структуру экспорта.

С началом «сланцевой революции» в США и Канаде происходит повышение доли топливного сырья, идущего на экспорт, однако преобладающую часть в экспорте этих стран по-прежнему (и с большим опережением) составляет промышленная продукция. Что касается Норвегии, то благодаря богатым нефтяным ресурсам, традиционно большая доля ее экспорта приходится на сырье, однако в экспорте этой страны столь же традиционно высока и доля промышленных товаров (около 20-25\%).

Таким образом, опыт других стран свидетельствует о том, что Россия, обладая богатыми природными ресурсами, отнюдь не обречена на вечную роль «мировой бензоколонки». Судя по решениям в области поддержки промышленного экспорта, принятым в последние годы, амбиции государства простираются значительно дальше. В связи с этим неизбежно встает традиционный русский вопрос: что делать?

Заметный вклад в решение этой проблемы в аналитическом плане внесли Всероссийская академия внешней торговли (ВАВТ) и Всероссийский научно-исследовательский конъюнктурный институт (ВНИКИ), которые в конце 2014 г. совместно подготовили обстоятельный, хорошо аргументированный документ «Национальная экспортная стратегия, спроецированная на 2030 год». В нем, в частности, проанализированы основные препятствия для роста экспорта промышленной продукции, среди которых такие 
застарелые проблемы, как высокие проценты по кредиту, рост тарифов на продукцию и услуги естественных монополий, высокая налоговая нагрузка, недостаточно развитая транспортная инфраструктура, сложность и длительность административных процедур и ряд других. Устранение большинства из них требует не только значительных затрат и усилий, но и длительного времени.

Пока удалось решить лишь некоторые проблемы, связанные в том числе с развитием промышленного экспорта. Это подтверждается, в частности, данными обзоров Всемирного банка, который ежегодно классифицирует страны по степени благоприятности условий для ведения бизнеса (Doing Business). Среди 180 стран, для которых определяется такой рейтинг, Россия в этом году переместилась с 64-го на 62-е место. На фоне того, что еще не так давно наша страна занимала в нем места, близкие к концу первой сотни, очевиден прогресс, свидетельствующий об определенном улучшении условий ведения бизнеса в России. Например, по одной из позиций рейтинга «регистрация предприятий» - Россия поднялась с 58-го на 34-е место, т.е. сразу на 24 пункта.

В то же время по целому ряду позиций в рейтинге Всемирного банка Россия сохраняет низкие места:по получению разрешения настроительство - 156-е; по доступности подсоединения к электрическим сетям - 143-е; по защите миноритарных инвесторов - 100-е. По показателю «положение в рамках международной торговли» позиция России в последнем выпущенном обзоре даже ухудшилась: она переместилась со 154-го на 155-е место (из имеющихся 189) (табл. 1).

\section{Таблица 1}

\section{Рейтинг в области условий ведения бизнеса}

\begin{tabular}{|l|l|l|l|}
\hline Индикатор & Москва & $\begin{array}{l}\text { Европа } \\
\text { и Центральная Азия }\end{array}$ & ОЭСР \\
\hline $\begin{array}{l}\text { Количество документов } \\
\text { для экспорта }\end{array}$ & 9 & 7 & 4 \\
\hline Время на экспорт, дни & 22,0 & 23,6 & 10,5 \\
\hline Стоимость экспорта, долл. за контейнер & 2705,0 & 2154,5 & 1080,3 \\
\hline $\begin{array}{l}\text { Стоимость экспорта, долл. за контейнер } \\
\text { (с поправкой на инфляцию) }\end{array}$ & 2705,0 & 2154,5 & 1080,3 \\
\hline Количество документов на импорт & 10 & 8 & 4 \\
\hline Время на импорт, дни & 20,0 & 25,9 & 9,6 \\
\hline Стоимость импорта, долл. за контейнер & 2920,0 & 2435,9 & 1100,4 \\
\hline $\begin{array}{l}\text { Стоимость импорта, долл. за контейнер } \\
\text { (с поправкой на инфляцию) }\end{array}$ & 2920,0 & 2435,9 & 1100,4 \\
\hline
\end{tabular}


Анализ проблем, которые Всемирный банк видит в российской системе ведения международной торговли, показывает, что, например, по сравнению со средними показателями стран ОЭСР, для экспорта у нас требуется 9 документов, тогда как в среднем по ОЭСР - только 4. Время, уходящее на экспорт продукции, в России составляет 22 дня, а в ОЭСР -10 дней. Россия значительно уступает странам ОЭСР и по показателям стоимости экспорта и импорта за контейнер. Так, если в Москве стоимость отгрузки контейнера в среднем составляет 705 долл., то в странах ОЭСР этот показатель почти в 3 раза меньше, что, естественно, значительно снижает накладные расходы для экспортных операций (табл. 2).

\section{Таблица 2}

Положение России в рейтингах условий ведения бизнеса

\begin{tabular}{|l|l|l|l|}
\hline \multirow{2}{*}{ Проблема } & \multicolumn{2}{|l|}{ Рейтинг } \\
\cline { 2 - 5 } & в 2015 г. & в 2014 г. & Изменение в рейтинге \\
\hline Регистрация предприятий & 34 & 58 & $\uparrow 24$ \\
\hline $\begin{array}{l}\text { Получение разрешений } \\
\text { на строительство }\end{array}$ & 156 & 172 & $\uparrow 16$ \\
\hline $\begin{array}{l}\text { Присоединение к электрическим } \\
\text { сетям }\end{array}$ & 143 & 141 & $\downarrow-2$ \\
\hline Регистрация собственности & 12 & 17 & $\uparrow 5$ \\
\hline Получение кредитов & 61 & 55 & $\downarrow-6$ \\
\hline Защита миноритарных инвесторов & 100 & 97 & $\downarrow-3$ \\
\hline Налогообложение & 49 & 48 & $\downarrow-1$ \\
\hline Международная торговля & 155 & 154 & $\downarrow-1$ \\
\hline $\begin{array}{l}\text { Обеспечение исполнения } \\
\text { контрактов }\end{array}$ & 14 & 14 & Нет изменений \\
\hline Разрешение неплатежеспособности & 65 & 62 & $\downarrow-3$ \\
\hline
\end{tabular}

Источник: Всемирный банк.

Таким образом, необходима серьезная систематическая работа всех ветвей государственной власти по улучшению условий ведения бизнеса, что будет способствовать выполнению и более общей задачи - расширению экспорта промышленной продукции. Не случайно, в рейтинге Doing Business Bceмирного банка Норвегия, США и Канада занимают соответственно 6-е, 7-е и 16-е места.

Однако в более общем плане речь должна идти о повышении конкурентоспособности российской экономики в целом (табл. 3). Безотлагательного решения требуют такие проблемы, как развитие производительного малого и среднего предпринимательства, составляющего экономическую основу большинства европейских стран, демонополизация экономики и развитие 
конкуренции, укрепление гарантий прав собственности, обеспечение независимости судебной и арбитражной системы, создание условий для привлечения иностранных инвестиций, эффективная борьба с коррупцией.

Это те общие проблемы, от которых России никуда не уйти. Конкретными проблемами регистрации, совершенствования документооборота и так далее заниматься также необходимо, но без радикального улучшения состояния экономики, без повышения ее конкурентоспособности принятие программ поддержки и развития экспорта вряд ли достигнет своей цели, что и показали прошедшие 20 лет.

\title{
Таблица 3
}

План развития России промышленного экспорта (2011 г. = 100\%), \%

\begin{tabular}{|l|l|l|l|l|l|l|}
\hline \multirow{2}{*}{ Контрольный показатель } & \multicolumn{2}{|l|}{ Год } \\
\cline { 2 - 7 } & $\mathbf{2 0 1 3}$ & $\mathbf{2 0 1 4}$ & $\mathbf{2 0 1 5}$ & $\mathbf{2 0 1 6}$ & $\mathbf{2 0 1 7}$ & $\mathbf{2 0 1 8}$ \\
\hline $\begin{array}{l}\text { Индекс роста } \\
\text { числа организаций- } \\
\text { экспортеров }\end{array}$ & 125,0 & 131,0 & 137,0 & 142,0 & 150,0 & 160,0 \\
\hline $\begin{array}{l}\text { Индекс роста } \\
\text { стоимости экспорта } \\
\begin{array}{l}\text { промышленной } \\
\text { продукции высокой } \\
\text { степени обработки }\end{array}\end{array}$ & 110,1 & 120,6 & 136,1 & 155,8 & 1801,1 & 205,5 \\
\hline
\end{tabular}

Источник: распоряжение Правительства РФ от 25 февраля 25014 г. № 259-р.

Эффективность недавно принятых секторальных программ промышленного развития еще предстоит оценить. Хочется надеяться, что они внесут свой вклад в повышение конкурентоспособности российской экономики.

\author{
Poluektov A. ${ }^{1}$
}

\section{Program of the Russian Federation on support of industrial exports: some observations}

$1 \quad$ Poluektov Aleksandr - chief expert of the Institute of trade policy Higher School of Economics, candidate of economic Sciences, worked at the Permanent mission of Russia to the $E U$, as well as the authorities responsible for foreign economic relations. 